\title{
Letzte Nachträge
}

Zu S. 35 Ende: Chaval „(junger) Bursche" kommt nach Corominas aus der Zigeunersprache; seine Heimat ist Andalusien. Aber die Zigeunersprache war nur die Vermittlerin des Wortes. In Wirklichkeit ist es arabischer Herkunft (ar. šâbb, pl. šubbân, šabāb, śábabat ,junger Mann von 16-30 Jahren“"); 》lo cierto es que el vocablo granadino de que nos ocupamos, era de uso común ... entre los moriscos del reino de Granada donde los gitanos lo oyeron e incorporaron a su ,caló‘ « (s. José Vázquez Ruiz, Sobre la etimología de chaval, chavea, chavó, RFE 40, 1956, S. 229-234).

Zu S. 38: Zum Einfluß der arabischen Musik auf die spanische s. Anuario Musical, CSIC, Barcelona 1946ff. passim (u. a. M. Schneider, A propósito del influjo árabe; ensayo de etnografía musical de la España medieval, An Mus 1, 1946, S. 181-194).

Zu S. 55: Eine alte lexikalische Gemeinsamkeit zwischen Nordostkatalonien und Südfrankreich scheint beim Typus RaTTA + PENNa zur Bezeichnung der Fledermaus vorzuliegen (pr. rato-penado; kat. rata-penada, ein Typus, der mit der Reconquista sich nach Süden bis in den valenzianischen Raum ausdehnte; s. M. Sanchis Guarner, Los nombres del murciélago en el dominio catalán, mit 1 Karte, RFE 40, 1956, S. 91-120).

Anm. zu S. 105: L. Mrchelena, Cuestiones relacionadas con la escritura ibérica, Emerita 23, 1955, S. 265-284.

Zu S. 110: Onomastik. - S. die Revue Internationale d'Onomastique, seit 1949 (Besprechung der Bände 1-7, soweit sie die Pyrenäenhalbinsel betreffen, durch M. Alvar, RFE 40, 1956, S. 336-339).

Zu S. 114 Corominas, JoAN letzte Zeile: Besprechung durch L. Spitzer, Modern Language Notes 71, 1956, S. 271-283, 373-386, mit zahlreichen Ergänzungen. - ORESTE MaCrí, Alcune aggiunte al dizionario di Joan Coro. minas, RFE 40, 1956, S. 127-170 [zahlreiche ergänzende Belege zu den ersten beiden Bänden $(\mathrm{A}-\mathrm{J})]$.

Zu S. 124: Geschichte. - Gómez Molleda, D.: Bibliografía histórica española 1950-1954, Madrid, CSIC, 1955, $491 \mathrm{~S}$.

Zu S. 125: Menéndez Pidal, R.: España y su historia, t. 1, Madrid 1957, 880 S.

Zu S. 128: Valdeavellano, L. G. DE: Historia de España, I: De los orígenes a la baja Edad Media, 2 a ed., Madrid 1956, 2 Bde, 514 und $694 \mathrm{~S}$.

Zu S. 128 Vázquez de PARGa: Steret, JaAN : Saint Jacques et les chemins de Compostelle. Avec 100 héliogravures et 9 cartes, Paris 1955, 148 S. [„,Kommentiertes Bilderbuch" H. Lausberg, Archiv 194, 1957, S. 94].

Zu S. 133: Caro Baroja, J.: Los moriscos del reino de Granada. Ensayo de historia social. Madrid 1957, 305 S. und 1 Karte. 
Zu S. 140: Saraiva, António Joski : História da cultura em Portugal, Vol. I, Lisboa 1950, $795 \mathrm{~S}$., mit zahlreichen Abb.

Zu S. 145: Caro Baroja, J.: Vasconia. (De historia y etnología.) Madrid 1957, $177 \mathrm{~S}$.

Zu S. 154 Skgor, JtaN : S. die positive Besprechung durch A. Badía, RFE 40, 1956, S. 254 f.

Zu S. 154: Serra, Glandomenico: Sostratos mediterraneos, RFE 40, 1956, S. 171-208. [Der 1. Teil (Cenni sullo sviluppo degli studi sul sostrato mediterraneo) enthält eine reichhaltige kritisch-bibliographische Utbersicht, insbesondere S. 175-181; der 2. Teil (Il sostrato mediterraneo alla luce degli studi sul paleosardo) enthält eine sorgfältige kritische Sichtung vorromanischer schon diskutierter Wörter; der 3. Teil (Strutturalismo del paleosardo) befaßt sich mit der Vokalstruktur und Reduplikation, wobei gelegentlich auch die Pyrenăenhalbinsel berührt wird (z. B. "La reduplicazione su due sillabe identiche, caratteristica del bilbilis iberico e del bilbil sardo assurge ad elemento di grande importanza storico-linguistica se lo compariamo con esempi analoghi ...\& S. 206)]. 
BALD IN GER

Die Herausbildung der Sprachräume auf der Pyrenäenhalbinsel 



\title{
DIE HERAUSBILDUNG DER SPRACHRÄUME AUF DER PYRENÄENHALBINSEL
}

\author{
QUERSCHNITT DURCH DIE NEUESTE FORSCHUNG \\ UND VERSUCH EINER SYNTHESE
}

Mit 13 Kartenskizzen

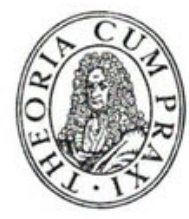

$\begin{array}{llllllllllllllllllllll}\mathbf{A} & \mathbf{K} & \mathbf{A} & \mathbf{D} & \mathbf{E} & \mathbf{M} & \mathbf{I} & \mathbf{E} & - & \mathbf{V} & \mathbf{E} & \mathbf{R} & \mathbf{L} & \mathbf{A} & \mathbf{G} & \boldsymbol{1} & \mathbf{B} & \mathbf{E} & \mathbf{R} & \mathbf{L} & \mathbf{I} & \mathbf{N}\end{array}$ 1958 
Copyright 1958 by Akademie-Verlag GmbH.

Alle Rechte fur die deutsche Ausgabe vorbehalten

Erschienen Im Akademie-Verlag GmbH., Berlin W 8, Mohrenstraße 39

Lizenz-Nr. $202 \cdot 100 / 494 / 68 \cdot M d I$ der DDR Nr. 4163

리요 Satz und Druck: VEB Leipziger Druckhaus, Leipzig (III/18/203)

Bestell- und Verlagsnummer: 5244

Printed in Germany 